\title{
"Centralized Statistics Courses at SMU: opportunity and advantage for SOR; research benefits for SMU"
}

Gezani Richman Miyambu
Maria Mokgadi Lekganyane
Solly Matshonisa Seeletse

Gezani Richman Miyambu, Maria Mokgadi Lekganyane and Solly Matshonisa ARTICLE INFO $\quad \begin{aligned} & \text { Seeletse (2017). Centralized Statistics Courses at SMU: opportunity and } \\ & \text { advantage for SOR; research benefits for SMU. Environmental Economics, 8(4), }\end{aligned}$ 37-43. doi:10.21511/ee.08(4).2017.05

DOI http://dx.doi.org/10.21511/ee.08(4).2017.05

RELEASED ON Wednesday, 06 December 2017

RECEIVED ON Sunday, 01 October 2017

ACCEPTED ON

Friday, 03 November 2017

\section{(cc) EY-No}

LICENSE

This work is licensed under a Creative Commons Attribution-NonCommercial 4.0 International License

JOURNAL

"Environmental Economics"

ISSN PRINT

$1998-6041$

ISSN ONLINE

1998-605X

PUBLISHER

LLC "Consulting Publishing Company "Business Perspectives"

FOUNDER LLC "Consulting Publishing Company "Business Perspectives"

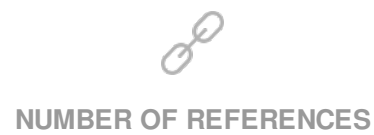

26
NUMBER OF FIGURES

0
NUMBER OF TABLES

0

(c) The author(s) 2022. This publication is an open access article. 
Gezani Richman Miyambu (South Africa), Maria Mokgadi Lekganyane (South Africa), Solly Matshonisa Seeletse (South Africa)

\title{
Centralized Statistics courses at SMU: opportunity and advantage for SOR; research benefits for SMU
}

\begin{abstract}
The Department of Statistics and Operations Research (SOR) at the Sefako Makgatho Health Sciences University (SMU) in South Africa offers courses in Statistics (Stats). Several departments in SMU campus require Stats training in their study program. In the interest of quality offering in Stats training and for statistical services needed for research, SOR offers to collect, centralize and facilitate all the Stats modules on campus. This paper then reflects on the impressions of academics and researchers on SMU campus regarding their view on centralized Stats courses in SMU. This will help explore the opportunities, envisaged research benefits and challenges for centralizing all the SMU Stats training in SOR.
\end{abstract}

Keywords: centralized courses, research support, statistics center, statistical services.

JEL Classification: D8, D83, E61, G34, I26, O31.

Received on: $1^{\text {st }}$ of October, 2017.

Accepted on: $3^{\text {rd }}$ of November, 2017.

\section{Introduction}

Sefako Makgatho Health Sciences University (SMU) is a newly established university from the former Medunsa campus of the University of Limpopo (UL) in the Gauteng Province of South Africa. Academic departments of SMU are housed in the schools which are headed by the deans. The SMU campus was initially the former Medical University of Southern Africa (MEDUNSA), which was established in 1978 as a health and medical institution for the underprivileged communities. In 1988 MEDUNSA introduced the Bachelor of Science degree programs due to a need to empower the local communities. The sciences were advancing in quality and quantity until the MEDUNSA merger with the former University of the North (Unin) of the Limpopo Province to form UL. Prior to this, Mathematics (Maths) and Stats courses were housed under the Department of Mathematics and Statistics. UL divided this department into the Department of Mathematics \& Applied Mathematics and the Department of Statistics \& Operations Research (SOR). SOR continued offering stats courses for the Bachelor of Science degree only, despite the

(C) Gezani Richman Miyambu, Maria Mokgadi Lekganyane, Solly Matshonisa Seeletse, 2017.

Gezani Richman Miyambu, Department of Statistics and Operations Research, Sefako Makgatho Health Sciences University, Gauteng Province, South Africa.

Maria Mokgadi Lekganyane, Department of Statistics and Operations Research, Sefako Makgatho Health Sciences University, Gauteng Province, South Africa.

Solly Matshonisa Seeletse, Department of Statistics and Operation Research, Sefako Makgatho Health Sciences University, Gauteng Province, South Africa.

This is an Open Access article, distributed under the terms of the Creative Commons Attribution-NonCommercial 4.0 Internationa license, which permits re-use, distribution, and reproduction, provided the materials aren't used for commercial purposes and the original work is properly cited.
Turfloop campus having Operations Research (OR) and centralizing all the Stats courses in their Stats and Operations Research department. It also did not exploit its advantage of an academic hospital to offer biostatistics (biostats). As a result, some academic departments proposed to put forward biostats degree programs, despite SOR's presence and them not being stats experts. SOR in an institution of higher learning (HLIs) can be a useful resource for research support services in addition to developing statisticians and many other possibilities. This paper explores the opportunities and challenges for centralizing all the SMU Stats training in SOR.

\section{SMU situation}

1.1. Contexts of Stats courses in SMU. Centralized curriculum enables expert growth where peers can augment one another and participate in similar activities of growth in the field (Seeletse \& Mokgwabone, 2016). There is a common loose tendency within SMU for departments to offer stats courses that are required as ancillary for their courses and degree programs. Many of the lecturers offering those courses are not trained statisticians. The reasons they offer these courses are that the lecturers assigned to lecture them have analyzed simple stats problems, and can calculate the mean and standard deviation. Or they can generate a few graphs from some packages. These lecturers know few concepts in basic stats, but do not participate in stats conferences and can neither present conference papers nor write academic manuscripts in the subject. Also, over the years the stats departments did not market themselves adequately to expand to offer these courses. On some previous occasions though, some Stats heads of departments on campus egotistically participated in part-time teaching of those courses/modules under those departments, and 
were remunerated in addition to their salaries in SOR. Therefore, the conceited desire outweighed the desire to develop SOR. Currently, the opportunity to secure those paying part-time jobs is available. However, participating in such opportunities by SOR members offsets the longterm determination of SOR's development.

Furthermore, SOR is a small department that required to develop. For the staff members of SOR, if a statistical support service center can be established in SMU, the center's success will be an opportunity to sustain research on SMU, and will be a definite advantage for SOR's postgraduate training. The long-term benefits for SMU will include improved and sustained research output.

1.2. Research prominence of SMU. As of 2016 year-end, SMU was not yet ranked in research performance among 26 South African universities. Over the years, SMU and its predecessor universities on the campus (MEDUNSA and UL) were also ranked lowly in research. SMU has an annual research day where oral and poster presentations are accepted for that day. Competitions are also held in which there are categories at individual and departmental levels for high participation and quality presentations. Among the limitations of these presentations, there is a lack of subject/discipline expert peer-review such as the mathematical and computing sciences, among others. In the judgement of competitions too, there seem to be biases away from these fields. Another weakness is that some of the papers read or presented at these platforms do not lead to research output on journals.

1.3. National universities' benchmark. Statistics departments in other South African universities perform statistical teaching services to support departments that need courses in Stats. To simplify the discussion, focus is only on the governmentaligned universities in South Africa (McGregor, 2010). The University of South Africa (Unisa) in Pretoria operated the Center for Applied Statistics (CAPSTAT). The University of Pretoria operates the STATOMET. Three (3) universities of the Western Cape Province also operate similar centers. KwaZulu-Natal University in KwaZulu-Natal Province, and Rhodes University in Eastern Cape Province, boast similar statistical service centers for researchers. In terms of research, these are among the leading universities nationally (HET, 2013). The common feature for those that lack such service centers is that they are also lagging behind in research.
1.4. Unique Unisa case vs SMU reality. When Unisa merged with the former Technikon South Africa and the former Vista University Distance Education Campus in 2005, the Department of Statistics in the newly formed Unisa proactively proposed to offer all the stats courses that were offered in different departments. The situation in merging campuses was much better than the SMU situation because the lecturers were all trained Stats experts. The disadvantage was that the disciplines in which those Stats courses were offered did not invest to develop the statisticians teaching the courses. Also, these statisticians were not developing fully as statisticians, but were always support staff of the main disciplines. In SMU, the situation is worse. Some lecturers teaching Stats courses in their own departments did not receive proper training in Stats. They lack knowledge of the underlying maths needed to inform data interpretations, and do not even participate in the environments and networks of statisticians. If the Unisa approach is adopted, then all the Stats courses and modules can be facilitated from a central point, which is the SOR. This setup can also aid to develop SMU's SOR and develop the SOR department into a magnificent service provider.

\section{Literature}

2.1. Best practice. According to Bretschneider, Marc-Aurele and $\mathrm{Wu}$ (2005), a best practice is a system that is generally accepted or empirically proven as superior to any options due to producing results that are superior to those achieved by other means or because it has become a standard procedure, such as a standard way of complying with legal or ethical requirements. Best practices are applied to maintain quality as an alternative to mandatory legislated standards, and can be based on self-assessment or benchmarking (Howell, 2013). In order to lead effectively, best practice is required.

According to Hussain and Howard (2013), modern organizations' common best practice includes assimilation of ICTs in their business processes. Feridun and Karagiannis (2009) define ICT as an extended term for information technology (IT), which emphasizes the role of integrated communications and the addition of telecommunications such as telephones and wireless signals, computers and the indispensable enterprise software, middleware, and audiovisual systems.

In academic institutions, best practice in statistical support for researchers occurs with the establishment of a dedicated service centers housed in a Stats department, using academics as the service providers and also using the centre for 
postgraduate training (Kvint, 2016). The service of such a center would also be used to generate funds as it charges for its services, and also reward the academics involved financially and other supports as a token for appreciating their contribution and to sustain the center. The technologies used in the centers include statistical packages and internet tools.

2.2. Quality. The term 'quality' refers to the level of excellence to the satisfaction on users, and the way it matches best practice, or fits the purpose for which it was intended. Drucker (2006) defines quality as the extent to which a product or service fits its purpose. Quality enforcement usually takes place through quality assurance, by examining the aims, structure, inputs, processes, outputs and projected outcomes. In HLIs, perceived high quality assists in attracting more students. Thus, the HLI which is perceived to be offering highest quality is likely to attract the best students. Actual quality in education would imply that the institution's graduates are leaders in their trade.

2.3. Ecological effect. Ecology, according to Irwin, Bronstein, Manson, and Richardson (2010), is the scientific examination and study of interfaces among organisms and their environment. It is essentially an interdisciplinary field, and includes the study of interactions that organisms have with each other, other organisms, and with abiotic constituents of their environment. Topics of interest to ecologists include the diversity, distribution, amount, and number of particular organisms, as well as cooperation and competition between organisms, both within and among ecosystems. Ecosystems consist of dynamically interacting parts including organisms, the communities they make up, and the non-living components of their environment. Ecosystem processes, such as key invention, pedogenesis, nutrient cycling, and several niche construction activities, regulate the flux of energy and matter through an environment. These processes are sustained by organisms with specific life history traits, and the variety of organisms is called biodiversity. Biodiversity, which refers to the varieties of species, genes, and ecosystems, enhances certain ecosystem services. Ecologists seek to explain:

- life processes, interactions, and adaptations;

- the movement of materials and energy through living communities;

- the successional development of ecosystems;

- the abundance and distribution of organisms and biodiversity in the environment.
Applied science and human social interactions are among the many practical applications of ecology (Swenson \& Enquist, 2008). Ecosystems sustain lifesupporting functions and produce natural capital. These include features of scientific, historical, economic, or intrinsic value.

2.3.1. Hierarchy. The scale of ecological dynamics can operate like a closed system while at the same time remains open with regard to broader scale influences (Bamber, 2012). Hence, ecologists classify ecosystems hierarchically by analyzing data collected from advanced scale units. They then assimilate this information to identify emergent patterns of uniform organization and processes that operate on various scales. To structure the study of ecology into a conceptually manageable framework, the biological world is organized into a nested hierarchy. In the setting of this study, the hierarchy ranges from Stats expertise, placement in SOR, statistical application with researchers at levels of student dissertation support, academic research consulting, academic planning and management (Peterson et al., 2011). Generally, this framework displays non-linear behaviors such that effect and cause are inconsistent. Minor variations in critical variables can cause disparate, perhaps irreversible, changes in the system properties.

2.3.2. Ecological niche. In ecology, Sahney, Benton, and Ferry (2010) describe a niche as the fit of a species living under specific environmental conditions. The ecological niche pronounces the way an organism or population responds to the distribution of resources and competitors, and the manner in which it in turn affects those same factors. In this study, the ecological amplification relationships are bound to occur in several ways.

\section{Problem statement}

The researchers in SMU require the services of statisticians. Some of them require analysis on basic concepts. Others inquire from statisticians on how to find ways to analyze qualitative data using quantitative methods. All these researchers studied short courses in Stats, but most were taught Stats by Stats-unqualified lecturers. If the Stats courses they studied were adequate, most researchers emerging from the SMU education system would be performing their own advanced statistical analysis. The statistical data analysis performed by some researchers of SMU lack modern state-of-the-art essence and are generally deficient (Matsose \& Seeletse, 2016). For example, data are analyzed using conventional methods without checking the outlier effects or distortions that may be caused on research results by influential observations. Actual Stats expertise contribution can offset all these flaws. 


\section{The purpose of the study}

The aim of the study was three-fold. These were to examine advantages of housing all SMU Stats courses in SOR; to determine the relative advantages of centralized Stats courses facilitation; and to assess the perception regarding placement of Stats services in the SOR.

\section{Materials and methods}

5.1. The study. A case study method was used, since one institution in this exploratory study, SMU was being investigated (Creswell, 2009). Document analysis was employed in which available documents were used to provide the setting of Stats courses, the facilitators of the Stats courses and the profiles of these facilitators. Some verbatim utterances of the departments that teach their own Stats courses were required. The arrangement of Stats courses being taught by non-experts is historical and regressive. It was inherited from the old MEDUNSA through UL into the current SMU. Nonetheless, this study needed to understand how the decision was reached (Yin, 2009) to use unqualified lecturers to teach Stats in a university. The syllabus documents and the guides used in that facilitation were analyzed.

5.2. Study design. The study design was qualitative, as it required verbose and not numeric responses (Gorard, 2013). It was concerned with issues of finding out if SMU researchers who were using statistical support services for their studies would welcome SOR hosting a research statistical service support center. It was also concerned that some Stats courses in SMU were facilitated by novices in Stats. In situations where researchers felt SOR was a suitable host for such a center, the study wanted to determine how they desired this center to be designed.

5.3. Study population. The SMU academics formed the study population, which, according to David and Sutton (2011), is the entire set of individuals under investigation. The total number of academics was about 360 . In order to ease sampling, a sampling frame was defined, which is an expedient subset of the study population from which sampling would be done (Fink, 2013). The sampling frame consisted of SMU academics who were active researchers, as well as representatives of departments which were teaching Stats modules for their qualifications. A total of about 35 active researchers formed the sampling frame.

5.4. Study sample. The study did not need to be representative of the entire study population. It only needed to determine SOR's perceived suitability to host a statistical support service center for SMU researchers, and the way such a center could be effusively useful. The study therefore required purposive sampling, which is a method using only the hand-picked responses who are familiar with the situation of the study (Creswell, 2014). The actual sampling method entailed targeting the SMU researchers who were coming to SOR offices to ask for statistical help from Stats lecturers. Since the expediency suited the researchers, the sampling method is known as convenience sampling (Braun \& Clarke, 2013). Convenience sampling is a method belonging to the general class of non-probability sampling methods (David \& Sutton, 2011).

5.5. Data collection. The main data collection tool used in the study was an interview guide. The reason for this method was to enable understanding of the respondents to explain in detail while writing and/or recoding the inputs made, and to probe where necessary (Graziano \& Raulin, 2013).

5.6. Data analysis. Thematic content analysis was used to analyze the data by forming themes from the phrases of the responses obtained from the research participants (Shaughnessy, et.al., 2012). In order to ensure that a complete account of responses was taken care of, phenomenology is also used. According to several authors (Somekh \& Lewin, 2011; Wertz et al., 2011), the researcher works towards an understanding of an individual's perceptions, perspectives and understanding of a given situation.

\section{Results}

6.1. Interview setting. Purposively and per convenience of communication, SMU researchers were questioned about their impressions on SOR's statistical services where they were assisted. They were also asked to indicate the way they felt about SOR housing a center for statistical support services given to researchers. Other questions that they were asked to answer were the way they wanted the statistical services to be rendered to them, and how far they wanted to be assisted. They were also probed on their level of Stats training they needed in order to enhance their practices, and to make their researches to be converted to pragmatic action plans.

6.2. Respondents. Academics in SMU who used Stats lecturers' consulting services for research and involved in research were targeted to assist with their experiences to assist in fashioning a statistical support service center. These respondents included professors and associate professors, head of departments (including acting ones), lecturers, and postgraduate students who were engaging in postgraduate student supervision and research. 
6.3. Interview procedure. The informal interviews took place gradually for 24 months. The first interaction started in March 2015 when SMU was launched. The frequency of interviews was about one respondent per month. The study was planned to stop when enough information was collected to design a beneficial statistical support service center. Therefore, some saturation point would have an indication of interview adequacy. Consistencies in responses were demonstrated, and some saturation was indicated after the ninth response. However, in order to optimize the design possibility, interviews continued until 22 responses were completed. The last interview took place in February 2017.

6.4. Responses. Many active researchers indicated severe desperation to have statistical support services on campus. Some of them pointed at their initial scepticism regarding SOR's potential to host such a center. They indicated to have been misinformed about deficient qualifications and experiences of the members in SOR. However, they then later realized that they were fed wrong information, and that their nattering informants were proved wrong over time. As a result, they wished to associate with and be served by SOR.

Most of the respondents did not want to be trained in hard-core Stats concepts. They wanted statisticians to establish a modern center and assist them with analysis. A few $(13.6 \%$, or 3 out of 22$)$ were willing to be given some training in order to perform some simple statistical analysis. The remaining $86.4 \%$ wanted statisticians to do analysis for them and also interpret the analysis for them.

Further, the researchers were interested in a situation where a statistician is allocated to a faculty/school, or a cluster of departments as a dedicated service provider on long-term bases. Most of them were not interested in the idea of Stats or biostats, as they did not want Stats training. Only the three $(13.6 \%)$ who wanted Stats training were also in favor of being trained in biostats. However, all the respondents agreed that training in biostats should be introduced for the academic development of students.

Surprisingly, the researchers were familiar with data capturing into some statistical packages such as EpiInfo, STATA and SPSS. They could also run the softwares to release results. However, they seemed to have lacked content knowledge of Stats, and also did not know which Stats methods were appropriate for which kind of studies. They claimed that they generated output based on certain concepts from their study supervisors, such as ANOVA and crosstabs. They indicated that their supervisors never related these concepts to their studies, but claimed that their supervisors insisted that no study can be completed without these concepts. The respondents also pointed out that these 'famous' concepts were a mystery to them.

The researchers were content that they were able to generate output and complete their study projects for graduation. Most of the respondents indicated that their researches do not always lead to publications. It seems that they target the SMU Research Day presentations.

The researchers complained that they did not receive encouraging support from the Research Directorate of SMU. They doubted the academic knowledge of the leading personnel on SMU. Funding, according to them, was made for workshops and training of non-researchers and for activities that did not have potential to lead to more research output. They also indicated that they doubted the directorate leaders' knowledge and commitment to research on campus. Apparently, refusals to approve funds for conferences and researches that are directly supporting the researches for which the research funds are allocated, are rife. These refusals are said to occur when the paper title seems different from the dissertation/thesis title from the perspective of the research directorate. The refusals by the research directorate to support these related activities are said to occur without consulting study supervisors. As a result, research is not supported. Also, the respondents also claim that the research directorate did not assist in linking campus researchers to SOR.

The idea of centralizing Stats courses in SOR was also found to be acceptable. It was viewed by the researchers as a growth opportunity for SOR. It was also viewed as having advantages of growth and research for both SOR and SMU's research community. Moreover, the success of such an approach was anticipated to be having long-term research benefits for SMU.

\section{Discussion}

Basically, the study discusses the possibilities of interactions and interfaces of experts in a way that described the ecology concept (Irwin et al., 2010). Researchers in SMU are diverse, distributed according to deployment, they are many, and in the service of SOR for Stats help, they are expected to cooperate as an ecosystem. This description is outlined in the responses.

The respondents were interested in SMU establishing a research support center for statistical services and to be housed in SOR. They also seemed 
to be interested in associating with SOR. One of their proposed models was to have a statistician from SOR dedicated or deployed to their departments for continual service support. Most of the respondents indicated their unwillingness to be trained in Stats to be self-sufficient in proficient data analysis. This, regrettably, is not one of the superlative approaches to empower researchers in Stats data analysis. Best practices focus on holistic empowerment and in this case it would imply preparing researchers to undertake some of their Stats analysis.

The situation being addressed entails statistical services to the campus researchers were not of a desirable level of quality. This is because the SMU research support from the research directorate, according to the respondents, was deficient and demoralizing. Their research day on campus also, did not seem to enhance research for publications to the extent that the presentations were occurring. The missing link from the research office to SOR was also disappointing to the researchers. There was noticeably a resilient necessity from SMU researchers to have a continual support for statistical services in their research.

\section{Conclusion}

The ecological effect is bound to occur with the interactions, interfaces and the networks that SOR services. As a specialist scarce discipline on campus, with few experts available in the SMU campus, Stats is a niche subject in SMU. Moreover, the unfolding of its proposed service structure could form a hierarchical niche by deploying SOR members to the different departments on campus.

The environment of SOR is suitable and conducive for the biostats center, and for statistical services for SMU researchers. The SMU researchers indicated their desperation in having vigorous statistical services inside SMU. The SOR services are used greatly, which was shown by the regular consultation visits of researchers to the department. Also, SOR showed to be necessary in SMU campus by researchers.

The idea of a statistical services support center in SOR was accepted as ideal for SMU's active researchers. The somewhat despised idea was for training of the researchers in Stats skills. Rather, the researchers mainly desire to be supported with the statistical services. They seemingly want statisticians to do the analysis for them than being trained to be self-sufficient. On the other hand, the idea of centralizing Stats courses at SOR for the entire SMU campus was embraced as a cheered initiative. It was also viewed as an opportunity and advantage for SOR, with the envisaged benefits of research for SMU as a whole.

\section{Recommendations}

The study recommends that:

- SMU Stats courses should be centralized in SOR, thus enabling a central point for the Stats ecosystem;

- a center should be established in SOR for research support to campus researchers and other Stats users;

- a proposal for the centralization should be developed and presented to SMU research leadership; and

- the idea to establish a statistical support service center should be proposed to relevant SMU authorities.

\section{Action plan}

The plan of this study is to develop a Stats ecological niche and establish a Stats resource center along those lines in order to provide research support to campus researchers initially, and then for assisting other Stats services users. The SOR leadership should develop a statistical service proposal for SMU researchers to relevant authorities, such as the Dean of School of Science and Technology, Deputy Vice Chancellor Research; Deputy Vice Chancellor Teaching and Learning, and particularly the Quality Assurance manager on SMU. Other stakeholders who should be consulted regarding the service center and centralization should be the SMU research leadership. The advantages of this option should be explained thoroughly to the influential figures on campus. These parties should also be requested to assist with ideas to optimize such an initiative.

\section{References}

1. Bamber, J. (2012). Shrinking glaciers under scrutiny. Nature, 482(7386), 482-483.

2. Beyer, H. L., Haydon, D. T., Morales, J. M., Frair, J. L., Hebblewhite, M., Mitchell, M., \& Matthiopoulos, J. (2010). The interpretation of habitat preference metrics under use-availability designs. Philosophical Transactions of the Royal Society B, 365(1550), 2245-2254.

3. Braun, V., \& Clarke, V. (2013). Successful qualitative research: A practical guide for beginners. Los Angeles: Sage Publications.

4. Bretschneider, S., Marc-Aurele, F. J., Jr., \& Wu, J. (2005). Best practices research: A methodological guide for the perplexed. Journal of Public Administration Research and Theory, 15, 307-323. 
5. Creswell, J. W. (2009). Research design. Case study. California: Sage Publications.

6. Creswell, J. W. (2014). Research design: Qualitative, quantitative and mixed methods approaches (4 ${ }^{\text {th }}$ ed.). University of Nebraska, Lincoln: Sage Publications.

7. David, M., \& Sutton, C. D. (2011). Social research: An introduction ( $2^{\text {nd }}$ ed.). London: Sage Publications.

8. Drucker, P. F. (2006). The effective executive: The definitive guide to getting the right things done. New York: Collins.

9. Feridun, M., \& Karagiannis, S. (2009). Growth effects of information and communication technologies: Empirical evidence from the enlarged EU. Transformations in Business and Economics, 8(2), 86-99.

10. Fink, A. (2013). Conducting research literature reviews: From the internet to paper (4th ed.). London: Sage Publications Ltd.

11. Gorard, S. (2013). Research design: Creating robust approaches for social science. London: Sage Publications.

12. Graziano, A. M., \& Raulin, M. L. (2013). Research methods: A process of inquiry ( $8^{\text {th }}$ ed.). New York: Pearson International Edition.

13. HET. (Higher Education \& Training) (2015). Report on the evaluation of the 2013 universities' research outputs. Pretoria: Department of Higher Education and Training.

14. Howell, K. E. (2013). Introduction to the philosophy of methodology. London: Sage Publications.

15. Hussain, M. M., \& Howard, P. N. (2013). What best explains successful protest cascades? ICT and the fuzzy causes of the Arab Spring. International Studies Review, 15, 48-66.

16. Irwin, R. E., Bronstein, J. L., Manson, J. S., \& Richardson, L. (2010). Nectar robbing: Ecological and evolutionary perspectives. Annual Review of Ecology, Evolution, and Systematics, 41(2), 271-292.

17. Kvint, V. (2016). Strategy for the global market: Theory and practical applications. London: Routledge.

18. Matsose, T., \& Seeletse, S. M. (2016). Biases from poor data analysis. American Journal of Applied Sciences, 13(10), 1053-1059.

19. McGregor, K. (2010). South Africa: New university clusters emerge. University World News, retrieved $31^{\text {st }}$ July 2017.

20. Peterson, A. T., Soberon, J., Pearson, R. G., Anderson, R. P. Martinez-Meyer, E. Nakamura, M., \& Araujo, M. B. (2011). Species-environment relationships. Princeton: Princeton University Press.

21. Sahney, S., Benton, M. J., \& Ferry, P. A. (2010). Links between global taxonomic diversity, ecological diversity and the expansion of vertebrates on land. Biology Letters, 6(4), 544-547.

22. Shaughnessy, J. J., Zechmeister, E. B., \& Zechmeister, J. S. (2012). Research methods in psychology (9 ${ }^{\text {th }}$ ed.). New York: McGraw-Hill.

23. Somekh, B., \& Lewin, C. (2011). Theory and methods in social research (2 ${ }^{\text {nd }}$ ed.). London: Sage Publications.

24. Swenson, N. G., \& Enquist, B. J. (2008). The relationship between stem and branch wood specific gravity and the ability of each measure to predict leaf area. American Journal of Botany, 95(4), 516-519.

25. Wertz, F., Charmaz, K., McMullen, L. M., Josselson, R., Anderson, R., \& McSpadden, E. (2011). Five ways of doing qualitative analysis: Phenomenological psychology, grounded theory, discourse analysis, narrative research and intuitive inquiry. New York: The Guilford Press.

26. Yin, R. K. (2009). Case study research: Design and methods (4 ${ }^{\text {th }}$ ed.). Singapore: Sage Publications. 